\title{
Exploring the challenges of implementing Participatory Action Research in the context of HIV and poverty
}

\author{
WARosenthal, MSc \\ School of Nursing, University of the Western Cape \\ DD Khalil, PhD MPA RN RNT \\ Division of Nursing \& Midwifery University of Cape Town
}

\section{Kev words}

Participatory Action Research, HIV/ AIDS, empowerment

\section{Correspondence address}

Mrs. Wendy Rosenthal

Address: Postnet 114

Private Bag X18

Rondebosch

7701

Tel:(021)959-3482

Email: wrosenthal@uwc.ac.za

\section{Abstract: Curationis 33 (2): 69-78}

HIV/AIDS is having a devastating impact on South Africa and particularly on poor communities. Empowerment of communities has been identified as an important step towards mitigating the consequences and helping communities to overcome the challenges presented. Participatory Action Research (PAR) has been identified as a useful methodology for the purpose of facilitating empowerment. This study explores the challenges involved in implementing PAR in the context of HIV/AIDS and poverty. In this article, the author describes a PAR project that took place in 2003/ 2004 with a group of five Xhosa speaking people living with HIV/AIDS in Masiphumelele, Cape Town. The aims of the study were to: 1 . Create an opportunity for the participants to engage in a participatory process aimed at self-awareness and empowerment. 2. To record and analyse this process with the intention of producing insight into the use of PAR in the context of poverty and HIV/AIDS and to identify the challenges involved.

The findings of this study highlight some important insights into the process of engaging people in the PAR process and the experiences of HIV positive people living in the context of poverty. The study explores the challenges involved in the process of empowerment and examines the process of "transferring" power and control from the researcher to the participants. Challenges were uncovered both from the point of view of the researcher who had to "let go of control" and participants who had to take on control. Participants struggled with issues of low self-efficacy and learned helplessness. Fluctuations in health also contributed towards alternating periods of hope and despair and these problems had an impact on their motivation to participate in the study. Lack of motivation to participate is a challenge highlighted in the literature and explored in this study. Participation is necessary for a study of this nature to be of benefit to the community, but unfortunately those most in need were found to be least likely to participate.

The study also critically examines the research process that was conducted and highlights the positive and negative contribution of the process towards empowerment. Certain aspects of the research process, including the contracting process, were identified as being problematic as they emphasize the power and control of the researcher rather than the participants. Recommendations for future research include: Promoting participation among the disempowered; the Contracting process and Power relations in PAR 


\section{Introduction}

This article describes a Participatory Action Research (PAR) project that took place in South Africa in 2003/2004. The participants in the research were a group of five black, Xhosa speaking, HIV positive people living in Masiphumelele, an informal settlement near Cape Town. PAR is an unusual research methodology, the purpose of which is not only to produce knowledge, but also to facilitate the empowerment of the participants and enable them to use the knowledge produced to improve their situation (Babbie and Mouton, 2001). PAR is not, however, a simple methodology and there are many challenges involved in the implementation (Cornwall and Jewkes, 1995; Gray, Fitch, Davis and Phillips, 2000). This article explores the challenges that took place in the PAR process and produces recommendations for future studies.

\section{Participatory Action Research}

PAR has proved to be an important tool for addressing issues of powerlessness. In PAR, the participants are seen as partners in the research process and not merely subjects of the study. This means that they are involved in shaping and directing the research and take part in the decision-making process (Cornwall and Jewkes, 1995). PAR involves "collective, self-reflective enquiry that is undertaken to improve a situation" (Koch, Selim and Kralik, 2002, p1 10). The process begins with examination and collaborative enquiry into the lived experiences of the participants. The participants are assumed to have essential and valid understandings and experiences, which are vital to comprehending their world and to bringing about change. New insights into the situation and the participants' lives are gained through the action reflection cycle, a key component of PAR. This cycle involves a circular process of action followed by reflection, followed by further action which is informed by the reflection phase. The goal of this cycle is for the researcher and participants to consciously engage in a process of learning from their actions (Zuber-Skerritt, 2001). From the new insights, which the participants gain into their experiences, the researcher helps to facilitate the planning of action to bring about change (Babbie and Mouton, 2001). The goal of PAR is to bring about meaningful change in the lives of the participants and the community. Change may come in the form of individual or group empowerment, increased capacity to problem solve, and/or the transformation of organisational structures (Cockburn and Trentham, 2002).

\section{Literature Review}

\section{Background and motivation for the study}

The HIV/AIDS pandemic has spread rapidly across the world to affect all nations. Not all groups, however, have been equally affected. HIV/AIDS has been particularly devastating to those sectors of society, which were already marginalised, powerless and vulnerable. It appears that a critical factor in the pandemic is the issue of power relationships. Those most affected are those who have little control over their lives. They are the most vulnerable to infection and the least able to deal with the consequences of the disease (Nelson and Wright, 1995; Van der Vliet, 1996). Just as the virus depletes the human body of its natural defenses, it also depletes the individual and family of their resources and ability to cope (Lyons, 1998). There is growing evidence that sustainable solutions for these kinds of problems cannot be found by experts alone. It is necessary for the people to be involved in finding their own solutions (Babbie and Mouton, 2001). Thus the motivation for this study is based on the need to engage people living with HIV/AIDS in an empowerment process aimed at finding their own solutions.

\section{The use of PAR in the study of HIVIAIDS and empowerment}

PAR has been employed extensively in the study of HIV/AIDS. For example, Kesby (2000) and Mabala and Allen (2002) studied how the community could be engaged in the prevention of the spread of HIV/AIDS. Lindsey, Stajduhar \& McGuinness (2001) report on a PAR intervention, which engaged the community in developing community-based organisations for caring for people living with HIV/AIDS. However, there appears to be a gap in the literature in the area of individual empower- ment in the context of HIV/AIDS and poverty. Some studies were found that focused on empowering individuals to address their personal needs in contexts other than HIV/AIDS (e.g. chronic illnesses (Koch and Kralik, 2001) and disability (Stewart and Bhagwanjee, 1999). These studies bear relevance to the current study as they also deal with chronic conditions and relatively marginalised groups and thus involve similar issues to those raised by the current study.

\section{Challenges in implementing PAR}

It is important to note that PAR is not a simple method to implement or an easy alternative to other research methods (Cornwall and Jewkes, 1995). Gray et al. (2000) point out that the nature of PAR and its emphasis on partnership and participant control, creates a number of challenges for the process of implementation. These include: problems in transferring control to the participants, conflicting expectations and agendas, problems in motivating people to engage in the research process and the time required for building partnerships.

\section{Contribution of this study}

The literature reviewed shows the great potential of PAR in helping people to gain control over their lives in disabling environments. However, a number of challenges have also been highlighted. In the context of the great need for sustainable solutions to the many problems caused by the HIV/ AIDS pandemic, it is believed that this study can make a worthwhile contribution by analysing the PAR process that was implemented, exploring its impact on empowerment and highlighting the challenges encountered in the process.

\section{Research problem / question}

What are the challenges involved in implementing PAR in the context of HIV and poverty?

Aims

- To create an opportunity for a group of people living with HIV/ AIDS to engage in a participatory process aimed at selfawareness and empowerment.

- To record and analyse the PAR 
Table 1 : Details of participants

\begin{tabular}{|l|l|l|l|l|l|l|}
\hline Name & Age & Sex & English & $\begin{array}{l}\text { Level of } \\
\text { Schooling }\end{array}$ & Disclosure of HIV status & Other information \\
\hline Zodwa & 40 & Female & Good & Grade 10 & $\begin{array}{l}\text { Disclosed publicly to } \\
\text { community. }\end{array}$ & $\begin{array}{l}\text { Most vocal member of group. } \\
\text { Mother of three children. She is } \\
\text { very concerned about what will } \\
\text { happen to her children when she } \\
\text { dies. }\end{array}$ \\
\hline Themba & 29 & Male & Good & Grade 12 & $\begin{array}{l}\text { Disclosed to family and } \\
\text { friends. }\end{array}$ & $\begin{array}{l}\text { Father of two children. Mother } \\
\text { of children died of AIDS. Pro- } \\
\text { vides for siblings as well as chil- } \\
\text { dren. }\end{array}$ \\
\hline Nandi & 30 & Female & Poor & Grade 10 & $\begin{array}{l}\text { Disclosed publicly to } \\
\text { community. }\end{array}$ & $\begin{array}{l}\text { Mother of one child. Shortly be- } \\
\text { fore the research began, she made } \\
\text { a dramatic recovery from being } \\
\text { in a wheelchair to being able to } \\
\text { walk again. }\end{array}$ \\
\hline Sindiswe & 21 & Female & Poor & Grade 10 & $\begin{array}{l}\text { Only to a few trusted } \\
\text { friends and family. }\end{array}$ & $\begin{array}{l}\text { Diagnosed HIV positive a few } \\
\text { months before research began. }\end{array}$ \\
\hline Thandi & 23 & Female & Very poor & Grade 10 & $\begin{array}{l}\text { Only to a few trusted } \\
\text { friends and family. }\end{array}$ & $\begin{array}{l}\text { Husband left her after finding out } \\
\text { about her status. }\end{array}$ \\
\hline
\end{tabular}

process with the intention of producing insight into the use of PAR in the context of poverty and HIV/AIDS

\section{Objectives}

- To engage the participants in a process of self-examination and reflection with the objective of helping them to gain new awareness about themselves; and to increase their level of empowerment

- To describe the challenges of facilitating PAR in the context of HIV/AIDS and poverty

\section{Research Design}

\section{Qualitative: Participatory Action Research (PAR)}

PAR was chosen as the most appropriate method of addressing the aims and objectives of this research. PAR is a qualitative method that focuses on participation, empowerment and taking action based on the knowledge generated by the research (Babbie and Mouton, 2001). This study recorded the PAR process that the researcher facili- tated with the participants and described the challenges involved.

\section{Sampling methods}

The participants in this study were five black, Xhosa-speaking adults living in Masiphumele, an informal settlement near Cape Town. The researcher made contact with the participants through the University of Cape Town (UCT) Memory Box Project in which they were participating at the time. The purpose of the Memory Box Project and the nature of the relationship between this project and the research is explained below:

\section{Collaboration with the Memory Box Training Project}

The Memory Box Training Project is an initiative aimed at involving people living with HIV/AIDS in a process of recording their life-stories and leaving for their families "intimate reminders of their lives" (Morgan, 2001, p18). A group of HIV positive people from the community are trained to run workshops for HIV positive people in the community in which they are taught how to make their own memory boxes.
The people fill their boxes with significant objects and write stories and draw pictures to provide an illustration of their lives. Memory boxes thus ensure that the family does not lose the memory of their loved one once they are gone (Morgan, 2001). The main focus of memory boxes and memory books is not, however, about dying of AIDS - it is about living with HIV. A variety of creative exercises are used to help the participants identify strengths, abilities and resources as well as weaknesses and obstacles (Morgan, 2001).

The Memory Box Project was chosen as a useful starting point for this study as the participants had already begun the process of self-examination and disclosure in the Memory Box training. Working through the Memory Box Project also facilitated access of the researcher to the community as the Memory Box Project was already established in the community. It also helped to provide continuity as the Memory Box Project continued after this study was finished. However, the partnership between the Memory Box 
Project and this research also led to an unanticipated problem. A misunderstanding arose between the researcher and the participants, where the participants assumed that they would be paid for their participation in the research as they had been paid for the Memory Box Project work.

\section{Gaining Entry}

The researcher asked the permission of the Memory Box Project facilitators to address the participants in the Memory Box Project and to invite them to take part in the research. At the first meeting the researcher explained the purpose of the research and invited the participants to take part in the research. It was explained to the participants that they were under no obligation to take part. All five members of the memory box project agreed to participate in the project.

\section{The Participants}

The participants included four women and one man. For the purpose of protecting their identities, the participants' names have been changed. Details about the participants are summarized in table 1 .

\section{Data Collection}

Data collection was a process within a process - that is, while the participants took part in the PAR process and gathered information on themselves, the researcher recorded how the PAR process unfolded.

Data collection was conducted by means of focus groups, which were tape-recorded and transcribed. A translator was employed for the sake of the group members who were not fluent in English. Focus groups were chosen as the most appropriate data collection method for this research as they allow the participants to interact with one another, share ideas, solve problems and make decisions together (Flick, 2002; Chiu, 2003). This study was designed to involve the participants in a PAR process aimed at empowerment and taking action against the disabling circumstances in their lives. The process was based on the Action Research steps described by Stringer (1999, p 18): "look", "think" and “act". Stringer's steps are a cyclical process involving a number of repetitions of the steps
(Stringer, 1999).

\section{Analysis}

The approach used for data analysis was qualitative content analysis. This approach was used as it is an effective method for analyzing transcript data and for organizing and simplifying data into meaningful themes (Patton, 1987). Analysis was done using the following techniques:

1. Immersion in the data This was done by listening to the tapes, reading the journal entries and reading through the transcriptions several times while taking notes (Creswell, 1998).

2. Coding and categorizing: In this process, the researcher identified themes in the transcripts and codes and categories were assigned in order to organize the data and make it more accessible for further analysis (Pope, Ziebland, \& Mays, 1999; Mason, 2002).

3. Developing pictorial representations: According to Pollock (1991, p 300) "the task at hand...is not to describe every piece of the jigsaw puzzle, but rather to stand back and paint a picture of the whole". The researcher developed a number of pictorial representations and tables to organise the information and to help the researcher gain an overall perspective of the data.

\section{Research Rigour Reliability of the Data and Data Capturing Methods}

A number of issues are important in evaluating the reliability and accuracy of tape-recorded data and transcriptions. Firstly, there is the sound quality of the recordings and the adequacy of the transcriptions and secondly, the inclusiveness of the data (Perakyla, 1997).

\section{- $\quad$ Accuracy of Tape-Recorded Data and Adequacy of Transcriptions}

Overall the sound quality of the tapes was good. However, in places there was some loss of data due to background noise. Accuracy of the transcriptions was checked by the re- searcher and by an independent consultant who checked both the transcription and the translation of the data. The consultant reported that there were some mistakes in the translation. However, in her opinion, the group discussion was translated and transcribed sufficiently accurately and in sufficient detail for the purposes of this research. In the presentation of findings, reference has been made to where data was lost or difficult to hear.

\section{- Inclusiveness of the Data}

Perakyla (1997) points out that taperecording can leave out certain aspects of the interaction under study and thus impact on the inclusiveness of the data. In order to address this issue, field notes were made immediately after the focus groups in order to capture other information that was not captured on the tape (e.g. seating arrangements, non-verbal behaviour, events that happened before and after the tape-recorded session etc.).

\section{Credibility}

According to Lincoln and Guba (1985), credibility refers to how accurately the findings reflect the reality of the study participants. In this study, member checking and peer debriefing were used to establish the credibility of the research results. These methods are described below.

\section{- $\quad$ Member checking}

Member checking involves taking the researcher's findings back to the participants and asking them whether these accurately represent their meanings (Garner, 1991; Mason, 2002). In this study, the researcher took the preliminary results back to the group members and they gave feedback indicating that they recognised their experiences in the descriptions given.

\section{- $\quad$ Peer debriefing}

Credibility can also be established by asking a colleague to review the analysis process and question the researcher on how he/she came to his/her conclusions. This is referred to as peer debriefing (Lincoln and Guba, 1985). In the current study, the researcher's supervisor was given the transcriptions to read and she was thus able to point out to the researcher when she had made assumptions about the data that 
might not be valid.

\section{Transferability}

Transferability/generalisability can be established by giving detailed descriptions of the context in which the research took place. This allows the reader to identify similarities to other contexts, and thus apply the results to similar settings (Lincoln and Guba, 1985). In this research, descriptions of the participants are given as well as the context in which they are living.

\section{Ethical Considerations}

The Council for International Organizations of Medical Sciences (CIOMS) (1993, p 10) requires that "all research involving human subjects should be conducted in accordance with three basic ethical principles: respect for persons, beneficence and justice." In this project, a number of processes were put in place to ensure these ethical principles were upheld. The proposal was submitted to the UCT Health Sciences Faculty Ethics committee for ethical clearance before the study commenced. Informed consent was taken before the process began. A detailed consent form in both English and Xhosa was given to the participants as well as being explained verbally. Participants were informed of their right to refuse to participate and to withdraw from the study. Confidentiality was maintained throughout the study. No names or personal details that could identify the participants have been used in this article or any other document relating to this study. The participants were wamed that they might find the intimate sharing of issues around their experience of HIV/AIDS distressing and they were assured that there would be support and counseling provided to them if necessary.

\section{Discussion of Findings}

The findings of this study highlight some important insights into the process of engaging people in the PAR process and the experiences of HIV positive people living in the context of poverty. In this section these findings are explored and compared to the findings of other studies.

\section{Engaging People to Participate in PAR}

Participation has been closely linked with empowerment. Research suggests that participation provides a key opportunity for individuals to obtain the skills, knowledge and critical awareness vital for empowerment. It is therefore important to understand what hinders or promotes participation (Prestby, Wandersman, Florin, Rich \& Chavis, 1990). Prestby et al. (1990) propose that in general people decide whether or not to participate by weighing up the perceived benefits of involvement and balancing it against the potential costs. Cornwall and Jewkes (1995) point out, however, that people's motivation to take part tends to fluctuate over time. As circumstances change and / or the participants discover that they are not going to get the benefits they expected to gain from involvement, motivation may dwindle (Cornwall and Jewkes, 1995). This is in fact what happened in this research study.

Zodwa: "I think from last year there were researchers from UCT who gave us money, so I think that is our problem. We were thinking maybe you were going to give us money because we were not working."

As the quotation above shows the participants expected to be paid for their involvement. The expectation of payment arose because the participants misunderstood the relationship between the UCT Memory Box Project and the researcher's study. The researcher entered the research site under the auspices of the UCT Memory Box Project and thus her study was assumed to also be a UCT project operating under the same conditions including payment of the participants. As a result, the participants entered the process with high motivation. This was not entirely motivated by payment: they also expressed excitement and hopefulness about the possibility of gaining skills and knowledge through the research process. However, a few weeks later, once they had realized they would not be paid for their time, their motivation and excitement dwindled and they eventually decided to withdraw. Thus, it appears that for the participants in this study, the benefits of engaging in the PAR process were attractive in the beginning, but not sufficient to continue their involvement once the realized that there would be no financial/material benefit.
It is not unusual that the prospect of a research study starting in a poor community, should evoke unspoken expectations of benefit on the part of the community members. Community members in the Brugge and Kole (2003) study, defined a successful research study as one that brought about benefit such as knowledge, resources and skills to the community. It is, in fact, important that the participants should perceive there to be benefits for them from taking part, in order to encourage them to get involved. However, as pointed out by Cornwall and Jewkes (1995), the researcher needs to be careful not to raise unrealistic expectations that cannot be fulfilled in the process of motivating the participants to take part. It is also important, as shown by this study, that the researcher is aware of the expectations the participants hold and negotiates with them around what is realistic in the context of the time and budget available to the project. Incentives to take part need not necessarily be financial, but they need to be suited to the participants' needs and what they perceive as valuable (Prestby et al., 1990). Prestby et al. (1990) found that the use of incentives and "cost management" strategies led to members of voluntary organisations having increased motivation to participate. Incentives used included: gifts, discounts on food, skills training, social events, giving praise and recognition at meetings etc. "Cost management" efforts included: keeping meetings short, providing child care, rotating duties amongst members, giving opportunity for people to express their views etc. These findings offer insight into what occurred in this research study, as well as giving insight into how future studies can encourage people to participate.

\section{Achieving Participant Control of the PAR Process}

Cornwall and Jewkes (1995) suggest that the key difference between participatory research and conventional research is in the area of power. Cornwall and Jewkes (1995) and Reid (2004) argue that in true participatory approaches, the control over the research process lies in the hands of the participants. They point out, however, that transferring power into the hands of the participants is a challenging proc- 
ess. Below, some of these challenges are explored.

\section{Power Imbalances: An Unequal Starting Point}

Brugge and Kole (2003) point out that researchers come into a poor community with a high level of power compared to the participants, because of their background of education and access to resources. This may be further enhanced in the minds of the participants who may perceive the researchers to be the experts and lack belief in their own knowledge and abilities. Gray et al. (2000) point out the need to be aware of this power differential when entering the research field. They advocate that researchers take special care to actively involve the participants in every aspect of the process, rather than just obtaining passive agreement to the researchers' agenda.

\section{Contracting: The First Contact}

The consent-taking process is often the first interaction that the researcher has with the participants and thus it has an important role in shaping the nature of the relationship between the researcher and participants. The usual method of taking consent in a research study involves using a pre-prepared consent form. However it is questionable whether this is the most appropriate and empowering way of engaging people in a PAR project as it is mostly a one-way process controlled by the researcher. This is contrary to the PAR principle of shared control. This oneway process may reinforce the expectation in the minds of the participants that the researcher is in control and they are to take a more passive role. It also emphasises the power differential between the researcher and the participants. It seems appropriate, therefore, that for this kind of research, alternative ways of engaging participants in the PAR process should be explored. Meyer (1993) suggests, the concept of "process consent". This refers to retaking consent as the process is adapted and changed. Thus it is not an alternative to the pre-prepared consent form, but it allows for flexibility and the involvement of the participants in shaping the process.

\section{Facilitator Issues - "Letting Go of Control"}

Kaplan and Alsup (1995) note that one of the potential obstacles in the transfer of power to the participants,is the inability of the researcher to "let go of control". Low, Shelley and O'Connor (2000) report that, in spite of having a sincere desire to relinquish control to the participants, they found themselves unintentionally taking over control at certain points in their study. Sometimes this was due to pressure from the participants who wanted them to take control. At other times, this came out of the assumption that the participants were not capable of taking responsibility for certain tasks. Low et. al.'s (2000) experience bears similarity to what occurred in this study. Although the researcher valued the principle of transferring power to the participants, she found herself unintentionally taking control for similar reasons. Researchers need to be constantly alert to this dynamic and to monitor the power dynamics in the process (Kaplan and Alsup, 1995). In Low et al. (2000), the researchers reflected on their actions in between each group session and attempted to take corrective action and hand back control to the group members in subsequent sessions. However, at times, the participants resisted this attempt to hand back the control to them. This raises another important aspect in power transfer, that of participant resistance.

\section{Participant Resistance}

Researcher: Okay, Nandi?...What would you like to happen [next in the research]?

Translater: (translating for Nandi) She say she would also like you to solve their problems.

In this study, the researcher found that the participants did not come up with ideas of their own, but tended to defer to the researcher's suggestions and look to the researcher for solutions, as the quotation above shows. In reference to this problem, Cornwall and Jewkes (1995) point out that PAR participants do not always want control of the process. They tend to prefer the researchers to control and decide things for them and come up with the ideas (Low et al., 2000). This can be for various reasons including: lack of belief in their own abilities (Brugge and Kole, 2003) or fear of the project becoming too time-consuming and burdensome (Gray et al. 2000). Gray et al.
(2000) suggest that researchers need to take extra time and effort to actively encourage participation in all aspects of the process. This includes nurturing the confidence of the participants in their own abilities and holding back one's own desire to rush in and "fix" the problem.

\section{Leamed Helplessness and Leamed Hopefulness}

Prilleltensky, Nelson and Peirson (2001) observe that power and control are not inherited attributes that an individual either has or has not; they are qualities that are developed by continual interaction with the environment. "Learned helplessness" theory, proposes that exposure to uncontrollable events will tend to lead to individuals losing motivation and feeling helpless. In contrast, "learned hopefulness" theory proposes that if individuals are given opportunities to exert control over their lives, their motivation and sense of control will increase (Zimmerman, 1990). Participating in community organisations or projects that offer individuals opportunities to learn new skills such as problem-solving and taking part in decision-making, can facilitate the process of building "learned hopefulness" and consequently empowerment. In the current study, all the participants come from impoverished backgrounds and have experienced a number of traumatic events in their lives over which they had no control (e.g. the death of loved ones due to HIV/AIDS, the loss of homes and financial security, rejection by friends and family etc.) According to the theories presented above, these circumstances are likely to have led to the participants feeling powerless and lacking motivation as is shown by the extracts below:

Translator - translating for Thandi: (describing the day she found out about her HIV status) Thandi said that there is nothing that makes her happy. Everything changed, because she knows that any day she can die.

Themba: "To stay without a job, because I am not working anymore that makes me sad. I don't want to sit doing nothing, because I'm going to steal from the others (LAUGHTER) and then I'm going to jail if I rob the others ..Staying without a job is something that makes me sad. Also think about 
every day, think about why I can't get ajob."

In this context, it is understandable that they should have developed a low sense of self-efficacy. This further explains why they resisted control being passed over to them, as having a low sense of self-efficacy, they lacked the confidence to take control and make decisions.

\section{Low Self-Efficacy}

According to Bandura (1997), people with low self-efficacy are likely to be demotivated, pessimistic about their chances of succeeding in life and are more likely to suffer from anxiety, sadness and depression. As a result, people with low self-efficacy are likely to lack the confidence and the motivation to participate in empowerment projects and if they do participate they are less likely to take an active part in the process. This presents a problematic situation: in order to be empowered, people need to take part, but in order to take part, they need to be empowered. This was a dilemma faced by this study. The researcher attempted to facilitate empowerment through giving the participants an opportunity to work on their problems with the support of the researcher and the group. However, the participants were not greatly convinced that they could successfully act against the disabling circumstances in their lives and therefore their motivation to make an attempt was low, as the quotation below reveals.

Researcher: Do you think it [solving problems together] can work?

Themba: I think so, but I'm not sure...(LAUGHS). I can't say yes it can work, I can't say no...

Cornwall and Jewkes (1995) and Reardon, Welsh, Kreiswirth \& Forester (1993) suggest that people can be encouraged to take on projects if their confidence is built up gradually by giving them small tasks and then increasingly larger responsibilities. Bandura (1997) suggests that another way of building self-efficacy is for the people to watch someone similar to themselves succeed at a task or successfully solve a problem.

\section{Hope and Despair in HIV}

Zodwa: "I was worried that time my
CD4 was 147 and I was very very weak and I was worried, because I think maybe I'm going to be sick, but now I feel very strong and healthy...very strong! So I'm always hoping that may be I'm going to be alive till the government get a cure for us...."

In this study, the participants described moments of deep despair and hopelessness alternating with moments of triumph and hope as shown in the quotation above. Cochrane (2003) and Kylmä, Vehviläinen-Julkunen \& Lähdevirta (2001) found uncertainty to be a predominant theme in the lives of people living with HIV/AIDS. This uncertainty was related to the unpredictable course of the disease and the experiences the participants had of recovering from serious illness to a sense of well-being, but never knowing when they would fall ill again. Participants in Cochrane's study described their experience as being like a "roller coaster" (Cochrane, 2003, p 385). Uncertainty is a normal part of human existence; however this is magnified by HIV (Cochrane, 2003). The participants in this study had already faced a great deal of uncertainty due to other factors in their lives, before their diagnosis with HIV/AIDS, for example, poverty, unemployment, death of loved ones. It seems that HIV/AIDS added another dimension to an already uncertain existence.

Kylmä et al. (2001) point out that fluctuations between hope and despair can have serious consequences for people living with HIV/AIDS. When hope is dominant, individuals are likely to have energy and motivation, but when despair or hopelessness is the overriding factor, the opposite is likely. This has implications for the empowerment process. Kylmä et al. (2001) recommend that people working with people living with HIV/AIDS, should be acutely aware of these mood changes. They suggest that professionals ask their clients about their sense of hope and despair and use interventions that foster hope. These recommendations, though aimed at nurses in a clinical setting, are also relevant for the empowerment process. Knowing where the participants are on the continuum of hope and despair, could be important for structuring the research process as periods of despair could negatively impact on the participants' ability to take part in the process.

\section{Conclusion and Recommendations}

PAR methodology offers an exciting alternative to the more traditional topdown, researcher controlled approach and holds out the possibility of achieving more effective and sustainable outcomes for communities. However, as this research has highlighted, there are many challenges involved in implementing the PAR process. Important findings are discussed below and recommendations for future research are made:

\section{Promoting participation among the disempowered}

In order for people to benefit from empowerment projects, they need to participate in these initiatives. However, as has been shown by this project, people in poverty-stricken circumstances are unlikely to participate unless they are given some kind of compensation or reward for their efforts, which contributes towards their struggle for survival.

This can be problematic as many projects lack the budget to give significant financial compensation. It is therefore recommended that research is undertaken on how people can be attracted to participate. This could involve studies which investigate how people's motivation is affected by nonmaterial benefits and how these could be marketed to potential participants.

\section{The Contracting Process}

In the current study, a particular area of concern was the contracting process. It was found that the contracting method used was not sufficiently participatory and an opportunity for empowerment and skills transfer was missed. It is recommended that further research is undertaken on how to make this process more participatory and empowering.

\section{Power relations in PAR}

Handing over control to the participants is a vitally important objective of PAR as it is through this process that the participants are empowered and given the opportunity to learn new skills. However, in this study, this process was blocked by a number of prob- 
lems, including, resistance from the participants and their lack of confidence in themselves. It is therefore recommended that further research is done on how this process can be effectively implemented and how the barriers such as low self-efficacy can be overcome.

\section{References}

BABBIE, E \& MOUTON, J 2001: The practice of social research. Cape Town: Oxford University Press.

BANDURA, A 1997: Self-efficacy. Harvard mental health letter. 13(9):4-6, March.

BRUGGE, D \& KOLE,A 2003: Acase study of community-based participatory research ethics: the healthy public housing initiative. Science and engineering ethics, 9:485-501.

CORNWALL, A \& JEWKES, $R$ 1995: What is participatory research? Social science and medicine. 41(12):16671676.

CHIU, LF 2003: Transformational potential of focus group practice in participatory action research. Action research, 1(2):165-183.

COCHRANE,J 2003: The experience of uncertainty for individuals with HIV/ AIDS. International journal of palliative nursing 9(9):382-388.

COCKBURN, L \& TRENTHAM, B 2002: Participatory action research: integrating community occupational therapy practice and research. Canadian journal of occupational therapy. 21-31, February.

COUNCIL FOR INTERNATIONAL ORGANIZATIONS OF MEDICAL SCIENCES (CIOMS) 1993: International ethical guidelines for biomedical research involving human subjects. Geneva: Council for International Organizations of Medical Sciences.

CRESWELL, JW 1998: Qualitative inquiry and research design: choosing among five traditions. London: Sage Publications.

FLICK, U 2002: An introduction to qualitative research. 2nd edition. London: Sage Publications.

GARNER, D 1991: Interpreting. (In Ely,
M, ed, 1999: Doing qualitative research: circles within circles. London: Falmer Press, p. 139-178.)

GRAY, RE; FITCH, M; DAVIS, C \& PHILLIPS, C 2000: Challenges of participatory research: reflections on a study with breast cancer self-help groups. Health expectations. 3:243-252.

KAPLAN, S \& ALSUP, R 1995: Participatory action research: a response to AIDS prevention in diverse communities. Convergence. 28(1):38-56.

KESBY, M 2000: Participatory diagramming as a means to improve communication about sex in rural Zimbabwe: a pilot study. Social science and medicine, 50(12):1723-1741.

KOCH, T \& KRALIK, D 2001: Chronic illnesses: reflections on a community-based action research programme. Journal of advanced nursing. $36(1): 23-31$.

KOCH, T; SELIM, P; \& KRALIK, D 2002: Enhancing lives through the development of a community-based, participatory action research programme. Journal of clinical nursing. 11(1):109. 112 , January.

KYLMÄ， J; VEHVILÄINENJULKUNEN, K \& LÄHDEVIRTA, J 2001: Dynamically fluctuating hope, despair and hopelessness along the HIV/AIDS continuum as described by caregivers in voluntary organisations in Finland. Issues in mental health nursing, 22:353-377.

LINCOLN, YS \& GUBA, EG 1985: Naturalistic inquiry. London: Sage Publications.

LOW, J; SHELLEY,J \& O'CONNOR, M 2000: Problematic success: an account of top-down participatory action research with women with multiple schlerosis. Field methods. 12(1): 29-48, February.

LINDSEY, E; STAJDUHAR, K \& MCGUINNESS, L 2001: Examining the process of community development. Joumal of advanced nursing 33(6):828835 .

LYONS, M 1998: The impact of HIV and AIDS on children, families and communities: risks and realities of childhood during the HIV epidemic. United Nations Development Programme: HIV and Development Programme. Issues Paper 30. www.undp.org/hiv/ publications.html. Accessed 9 March 2009

MABALA, R \& ALLEN, K 2002: Participatory action research on HIV/AIDS through a popular theatre approach in Tanzania. Evaluation and program planning. 25(4):333-339.

MASON, J 2002: Qualitative researching. 2nd edition. London: Sage Publications.

MEYER, JE 1993: New paradigm research in practice: the trials and tribulations of action research. Journal of advanced nursing, 18:1066-1072.

MORGAN, J 2001: Boxes and remembering in the time of AIDS. AIDS hulletin, 10(2):17-20.

NELSON, N \& WRIGHT, S 1995: Power and participatory development: theory and practice. London: Intermediate Technology Publications.

PATTON, MQ 1987. How to use qualitative methods in evaluation. Los Angeles : Sage Publications.

PERAKYLA, A 1997: Reliability and validity in research based on transcriptions. (In Silverman D, ed. 1997: Qualitative research: theory methods and practice. London: Sage Publications, p. 201-220.)

POLLOCK, LC 1991: Qualitative analysis. (In Cormack, DFS, ed. 1991: The research process in nursing. 2nd edition. Oxford: Blackwell Science Ltd, p. 293-302.)

POPE, C; ZIEBLAND, S \& MAYS, N 1999: Analysing qualitative data. (In Pope, C \& Mays, N, eds. 1999: Qualitative research in health care. 2 nd edition. Bristol: BMJ Books, p. 75-88.)

PRESTBY, JE; WANDERSMAN,A; FLORIN, P; RICH, R \& CHAVIS, D 1990: Benefits, costs, incentive management and participation in voluntary organizations: a means to understanding and promoting empowerment. American joumal of community psy- 
chology, 18(1):117-149.

PRILLELTENSKY, I; NELSON, G\& PEIRSON, L 2001: The role of power and control in children's lives: an ecological analysis of pathways toward wellness, resilience and problems. Journal of community and applied social psvchology, 11:143-158.

REARDON, K; WELSH, J; KREISWIRTH, B \& FORESTER J 1993: Participatory action research from the inside: community development practice in East St. Louis. American sociologist. 24(1): 69-92, Spring.

REID, C 2004: Advancing women's social justice agendas: a feminist action research framework. International journal of qualitative methods. 3(3):122, September.

STEWART, R \& BHAGWANJEE, A 1999: Promoting group empowerment and self-reliance through participatory research: a case study of people with physical disability. Disabilitv and rehabilitation, 21(7):338-345.

STRINGER, E 1999: Action research. 2nd edition. London: Sage Publications.

VAN DER VLIET, V 1996: The politics of AIDS. London: Bowerdean Publishing Company Ltd.

ZIMMERMAN, MA 1990: Toward a theory of learned hopefulness: a structural model analysis of participation and empowerment. Journal of research in personality. 24:71-86.

ZUBER-SKERRITT, $O$ 2001: Action learning, action research and process management: theory, practice, praxis. Brisbane: Action Research Unit, Faculty of Education, Griffith University. 